\title{
$\mathrm{ACF}$ 를 이용한 휘발성 유기화합물(VOCs)의 흡착/탈착 특성
}

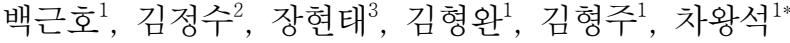 \\ ${ }^{1}$ 군산대학교 토목환경공학부, ${ }^{2}$ (주)유성환경, ${ }^{3}$ 한서대학교
}

\section{Adsorption/Desorption Properties of VOCs on Activated Carbon Fiber}

\author{
Geun-Ho Baek ${ }^{1}$, Jung-Su Kim ${ }^{2}$, Hyen-Tae Jang ${ }^{3}$, Hyeong-Wan Kim ${ }^{1}$, \\ Hyeong-Joo $\mathrm{Kim}^{1}$ and Wang-Seog $\mathrm{Cha}^{1 *}$ \\ ${ }^{1}$ School of Civil and Environmental Engineering., Kunsan Nat'l University, \\ ${ }^{2}$ Yousung CO., Ltd, \\ ${ }^{3}$ Dept. of Chem. Eng., Hanseo university
}

\begin{abstract}
요 약 기존에 주로 사용되었던 활성탄을 대체할 수 있는 활성탄소섬유를 이용하여 휘발성 유기화합물질의 흡탈착 특성을 연구하였으며, 고정층을 이용하여 흡착 및 파과특성을 조사하였다. 활성탄소섬유중 $\mathrm{ACFJ}$ 의 경우가 활성탄에 비하여 약1.15배 높은 흡착량을 보였으며, 흡착층의 온도가 증가함에 따라 파과시간 및 흡착량은 감소하였다. 또한 활 성탄의 경우 약 $99 \%$ 까지 탈착하는데 20 분이 소요되었으며, 활성탄소섬유의 경우 약 $99 \%$ 탈착되기까지 5 분이 걸려 활성탄소섬유가 약 4 배 빠르게 탈착됨을 알 수 있었다.
\end{abstract}

\begin{abstract}
We investigated the adsorption/desorption property of volatile organic compounds(VOC) by using activated carbon fibers(ACF) instead of activated carbon(AC) which is conventionally used. The adsorption behavior of the fixed bed and the breakthrough characteristics were also studied. As a result, ACFj showed 1.15 times higher adsorption amount as compared to AC. The breakthrough Point and adsorption amount of VOCs were decreased with the increase of temperature. In the case of $\mathrm{AC}$, desorption time having $99 \%$ removal efficiency was about as minutes, but that of ACF was about 5 minutes at same condition.
\end{abstract}

Key Words : VOCs(Volatile Organic Compounds), ACF(Activated Carbon Fibers), Adsorption, Desorption, AC(Activated Carbon)

\section{1. 서론}

대기 중에 존재하는 오염물질은 그 배출원에 따라 자 연적 배출원과 인위적 배출원으로 구분되며 특히 인간의 문명 및 문화 발전에 의해 점차 인위적 오염원의 기여도 가 더욱 중요시되어지고 있다. 이러한 여러 유형의 오염 물질들은 그 화학적 특성에 따라 대기질에 미치는 영향 또한 다양하며 대기 중에서 화학적 변화를 통해 새로운 형태의 오염물질로 존재하고 있음이 밝혀지고 있다. 최근 단일성분의 오염물질들에 대한 지속적인 관리로 이들 물 질에 대한 처리기술은 확보되었으나, 산업 현장에서 새롭

교신저자 : 차왕석(wscha@kunsan.ac.kr)

접수일 11년 03월 03일 수정일 11년 04월 19일
게 생성되는 많은 양의 복합물질들에 의한 오염 또한 관 심의 대상이 되기 시작하였다. 특히 대기 중에서 오존의 생성과 밀접한 관련이 있는 휘발성 유기화합물(VOCs : Volatile Organic Compound)에 대한 관심은 점점 증가하 여 현재 여러 분야에서 연구되어지고 있는 실정이다[1,2].

휘발성 유기화합물의 처리 방법으로는 연소법, 생물학 적 처리법, 흡착법 등이 대규모 공정에 활발하게 적용되 고 있으며, 특히 연소법이 가장 상용화되어 있다. 이러한 방법들은 휘발성 유기화합물이 일정한 농도로 연속하여 발생되는 경우에 유리하지만 단속적이거나 소규모, 간헐 적인 발생원에 대해서는 경제적인 면에서나 기술적인 면 에서 적용이 어렵다. 그러나 흡착법은 기공이 잘 발달된 게재확정일 11 년 05 월 12 일 
흡착제를 이용하여 다른 가스와 혼합된 휘발성 유기화합 물의 성분을 물리흡착 또는 화학 흡착하여 분리, 제거하 는 기술로서 흡착제로는 실리카겔, 활성탄, 제올라이트, 알루미나 등이 사용되고 있다. 특히 활성탄을 이용한 흡 착법은 휘발성 유기화합물의 농도 및 각종 부하에 대한 대응성이 좋고, 촉매소각법과 비교하여 저렴한 가격과 특 정 물질에 대한 독성을 보이지 않는 장점을 가지고 있어 현재 많이 사용되어지고 있다. 그러나 2차 오염물의 발생 과 과도한 압력 손실, 높은 분진 발생률, 재생사용의 어려 움 등의 단점을 가지고 있어 이를 보안하기 위한 모색이 필요한 실정이다[3-5].

활성탄소섬유는 표면에 미세 기공이 잘 발달하여 질소 산화물, 황산화물 등을 처리하는 연구에 활발히 이용되고 있으며, 휘발성 유기화합물의 처리에도 시도되고 있다. Jing 등은 레이온계 활성탄소섬유를 이용하여 포름알데 히드를 흡착하는 연구를 수행하였고[6], Luo 등은 활성탄 소섬유를 다양하게 성형하여 휘발성 유기화합물의 흡착 에 사용하고 전기를 이용한 가열방식을 통해 재생하는 연구를 하여 적용 가능성을 넓혔다[7]. 이렇듯 최근에 휘 발성 유기화합물을 활성탄소섬유에 흡착하는 연구가 활 발히 진행되고 있다.

본 연구에서는 기존에 주로 사용되었던 활성탄을 대신 할 수 있는 활성탄소섬유를 이용하여 대표적 휘발성유기 화합물질인 톨루엔과 MEK (Methyl Ethyl Ketone)의 흡 탈착 특성, 그리고 다양한 공정조건에 대한 영향도 조사하였다.

\section{2. 실험 장치 및 방법}

\section{1 실험장치}

본 실험에 사용한 실험장치의 개략도는 그림 1 과 같 다. 실험 장치는 크게 유량조절부, 증기발생부, 흡착제 충 진층, 분석부로 구성되어 있다. 실험장치 시스템은 전체 적으로 $1 / 4$ inch 테프론 재질의 튜브를 이용하여 주요 장 치들을 연결하였다. 유량조절부에서는 휘발성 유기화합 물 제조에 사용된 공기를 일정한 유량으로 주입할 수 있 도록 MFC(Mass Flow Controller)를 사용하였다. 증기발 생부에서는 $\mathrm{MFC}$ 로 조절된 공기를 톨루엔 또는 $\mathrm{MEK}$ 가 담긴 용기에 주입하여 다양한 농도의 휘발성 유기화합물 이 제조되도록 하였으며 또한 농도의 교란을 최소화하기 위해 mixing chamber를 두었다. 유리재질의 흡착실험용 반응기는 직경 $10 \mathrm{~mm}$, 길이 $450 \mathrm{~mm}$ 이며, 반응기 중간에 glass fritz를 두어 충전된 흡착제를 고정할 수 있게 하였 다. 반응기 주위로 흡착 실험시 흡착층의 온도 유지와
탈착 실험시 흡착층 가열을 위해 IR 히터를 장착하였으 며, 흡착층 하부에 $\mathrm{K}$ 형 열전대을 장착하여 IR 히터를 조 절하였다.

분석부에서는 4 방 밸브를 사용하여 휘발성 유기화합 물의 흡착전과 후의 농도를 on-line으로 측정할 수 있도 록 구성하였으며 분석은 $\mathrm{GC}$ (gas chromatography), FID(Flame Ionization Detector)을 사용하여 분석하였다.

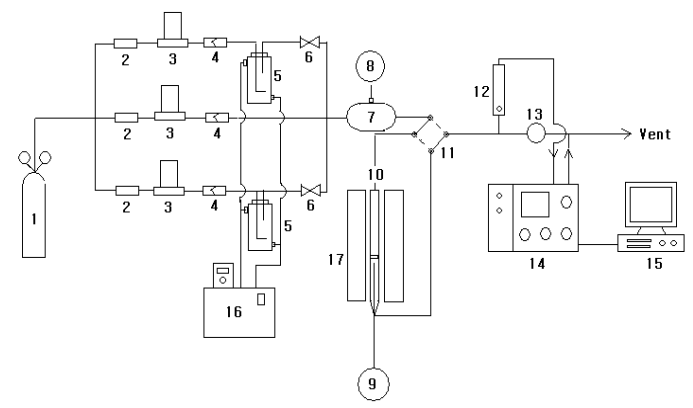
1. Air
2. Filter
3. MFC(Mass Flow Controller)
4. Check valve
5. VOCs generator
7. Mixing chamber
6. 2-way valve
9. $\mathrm{T} / \mathrm{C}$
8. PI
11. 4-way valve
10. Reactor
13. Micro valve
12. Flow mater
15. Computer
14. G.C
17. IR heater
16. Water bath

[그림 1] 휘발성 유기화합물 흡착실험을 위한 실험장치 개 략도

\section{2 흡.탈착 실험방법}

$\mathrm{ACF}$ 에 흡착물 이외의 물질이 흡착되는 것을 최소화 하기 위해 실험 수행 전에 $200^{\circ} \mathrm{C}$ 의 불활성 분위기에서 4 시간 동안 소성시킨 후 사용하였다. 흡착 실험전 흡착반 응기에 $\mathrm{ACF}$ 를 일정량 충전하고 공기를 흘리면서 흡착온 도를 일정하게 유지하였다. 흡착온도에 도달하면 3 방 밸 브를 사용하여 일정농도의 휘발성 유기화합물이 흡착반 응기에 유입되도록 하였다. 흡착반응기에서 배출되는 휘 발성 유기화합물의 농도는 연속적으로 실시간 측정하였다.

휘발성 유기화합물의 농도측정 곡선으로부터 흡착된 양을 Simpson rule을 이용하여 계산하였으며, 흡착이 완 료된 후 $\mathrm{AFC}$ 의 무게를 측정하여 계산 값과 실제 측정값 을 비교하였다.

탈착실험은 흡착제가 휘발성 유기화합물에 의해 충분 히 포화된 이후에 실시되었으며, IR히터를 이용하여 탈 착실험에 있어 중요한 운전조건인 신속한 온도상승이 이 루어지도록 하였다. 
3. 실험결과 및 고찰

\section{1 활성탄소섬유의 흡착 특성}

\section{1 .1 활성탄소섬유의 제조사별 흡착 특성}

각각 중국 및 일본에서 제조된 $\mathrm{ACF}_{\mathrm{Cl}}, \mathrm{ACF}_{\mathrm{C} 2}, \mathrm{ACF}_{\mathrm{J}}$ 흡착제를 사용하여 흡착층에 각각 $0.03 \mathrm{~g}$ 을 충전한 후 톨 루엔에 대한 흡착특성을 조사하였다. 이때 실험조건은 흡 착층 온도 $25^{\circ} \mathrm{C}$, 유속 $500 \mathrm{cc} / \mathrm{min}$, 수분함량 $0 \%$ 이었으며 주입된 톨루엔의 농도는 $100 \mathrm{ppm}$ 이었다.

그림 2는 활성탄소섬유의 종류에 따른 흡착진행과정 을 나타낸 그림이다. 표 1 에서 제시된 각 활성탄소섬유의 비표면적을 고려하면 흡착제의 표면적 증가에 따라 파과 시간이 길어지는 것을 확인할 수 있다. 이러한 현상은 비 표면적이 증가하면서 흡착이 이루어지는 MTZ의 길이가 증가하기 때문이며 이러한 $\mathrm{MTZ}$ 의 길이의 증가는 $\mathrm{ACF}_{\mathrm{J}}$ 의 기공 입구에서부터 시작된 높은 흡착비율 때문이다. 톨루엔이 화학적으로 안정한 점을 고려하면 비표면적이 가장 큰 $\mathrm{ACF}_{\mathrm{J}}$ 가 가장 느린 파과시간을 보여주고 있고, 비표면적이 가장 적은 $\mathrm{ACF}_{\mathrm{C} 2}$ 가 가장 빠른 파과시간을 나 타냈다. 이러한 결과는 이승재 등의 연구에서도 본 연구 와 유사한 결과를 보이고 있다[5].

그림 3은 활성탄소섬유와 활성탄의 흡착특성을 상호 비교한 그림이다. 그 결과 breakthrough curve가 $\mathrm{ACF}_{\mathrm{Cl}}$ 보다 활성탄이 빠른 배출 특성을 보였으며, 안정화가 되 기까지 많은 시간이 소요되는 것을 볼 수 있다. 이러한 이유는 활성탄은 mesopore나 macropore가 micropore와 같이 공존하고 있기 때문이며 이들이 차지하는 pore volume의 분율이 커지고 이로 인하여 흡착물의 모세관 응축현상이나 확산이동이 흡착시간을 증가시키기 때문이 다[8].

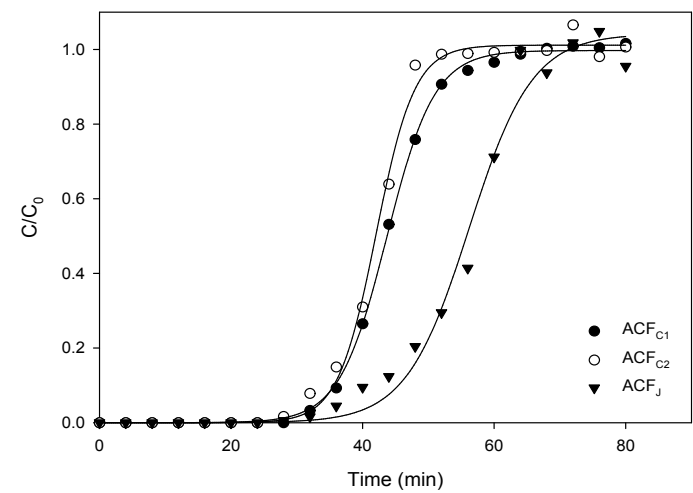

[그림 2] ACF종류에 따른 흡착 특성

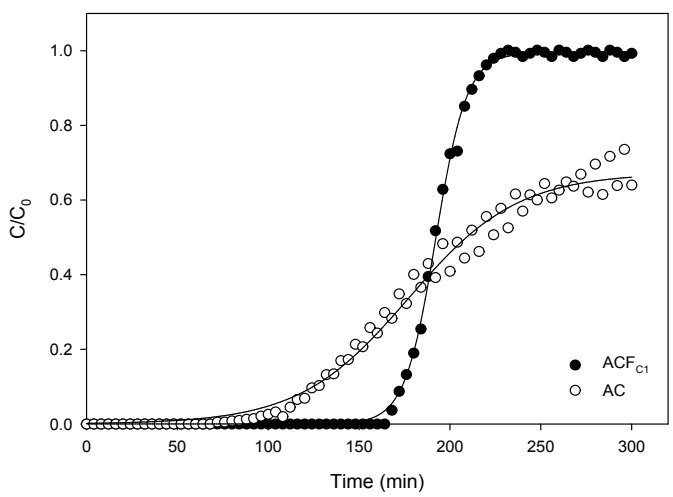

[그림 3] $\mathrm{ACF}$ 종류에 따른 흡착 특성

또한 그림 2 와 그림 3 을 바탕으로 계산되어진 각 흡착 제의 흡착량은 표 2에 나타냈다. 실제 흡착제 단위무게 당 흡착되어지는 양은 가장 큰 표면적을 가지는 $\mathrm{ACF}_{\mathrm{J}}$ 가 가장 좋은 것임을 알 수 있다. 변용수 등은 활성탄, 활성 탄소섬유, 제올라이트를 사용한 톨루엔의 평형흡착능력 의 비교 연구에서 활성탄소섬유가 활성탄에 비해 1.43 배 높다고 보고한 바 있다[2]. 본 연구에서도 유사하게 $\mathrm{ACF}_{\mathrm{J}}$ 가 활성탄에 비해 약 1.15 배 높은 결과를 나타내었다.

흡착속도에 있어 $\mathrm{ACF}_{\mathrm{Cl}}$ 은 $0.00267 \mathrm{~mole} / \mathrm{min}$ 이고, $\mathrm{AC}$ 의 경우 $0.00179 \mathrm{~mole} / \mathrm{min}$ 인 것으로 측정되었다. 활성탄 소섬유가 활성탄에 비하여 약 1.5 배 가량 흡착속도가 빠 른 이유는 실험에 사용한 $\mathrm{ACF}_{\mathrm{Cl}}$ 의 경우 활성탄에 비해 기공의 분포가 비교적 균일하므로 톨루엔 등과 같은 휘 발성 유기화합물의 확산 이동이 훨씬 빠르기 때문이다.

[표 1] 활성탄소섬유 및 활성탄의 물성특성

\begin{tabular}{|c|c|c|}
\hline 흡착제 종류 & $\mathrm{BET}\left(\mathrm{m}^{2} / \mathrm{g}\right)$ & 원산지 \\
\hline \hline $\mathrm{ACF}_{\mathrm{C} 1}$ & 1296 & 중국 \\
\hline $\mathrm{ACF}_{\mathrm{C} 2}$ & 960 & 중국 \\
\hline $\mathrm{ACF}_{\mathrm{J}}$ & 1769 & $\begin{array}{c}\text { Toyobo } \\
\text { 일본 }\end{array}$ \\
\hline 활성탄 & 1100 & \\
\hline
\end{tabular}


[표 2] 흡착제 종류에 따른 흡착량

\begin{tabular}{|c|c|c|c|c|}
\hline & $\mathrm{ACF}_{\mathrm{C} 1}$ & $\mathrm{ACF}_{\mathrm{J}}$ & $\mathrm{ACF}_{\mathrm{C} 2}$ & 활성탄 \\
\hline $\begin{array}{c}\text { 흡착량 } \\
\text { (g/g of } \\
\text { adsorbent) }\end{array}$ & 0.37 & 0.39 & 0.29 & 0.34 \\
\hline
\end{tabular}

\section{1 .2 휘발성 유기화합물 종류별 흡착특성}

활성탄소섬유의 흡착실험 및 흡착공정의 설계시 가장 중요한 부분은 흡착물질을 결정하는 것이다. 대상 흡착물 에 따라 흡착량과 흡착시간 등이 크게 달라지기 때문이 다. 그림 4는 $\operatorname{VOC}($ 톨루엔, MEK, 아세트알데히드) 종류 에 따른 $\mathrm{ACF}_{\mathrm{Cl}}$ 흡착제의 흡착특성을 나타낸 그림이다.

그림 4에서 흡착제에 흡착되는 양은 톨루엔> $\mathrm{MEK}>$ 아세트알데히드 순서인 것으로 나타냈다. 이러한 현상은 주입되는 흡착물의 분자량 차이에 의한 것으로 예상되며, 손미숙 등도 본 연구와 유사한 연구결과를 보고한 바 있 다[3]. 또한 표 3 은 상기의 실험결과를 바탕으로 $\mathrm{ACF}_{\mathrm{Cl}}$ 의 $\mathrm{VOC}$ 종류별 흡착량을 나타낸 표이다. 상기와 같이 분자 량이 높은 $\mathrm{VOC}$ 가 많은 흡착량을 보인 이유는 기공 내부 로의 확산이 보다 느리고 그에 따라 $\mathrm{MTZ}$ 의 길이(두께)가 길어져 파과시간이 증가하여 흡착되어지는 양도 상대적 으로 높게 나타기 때문이다.

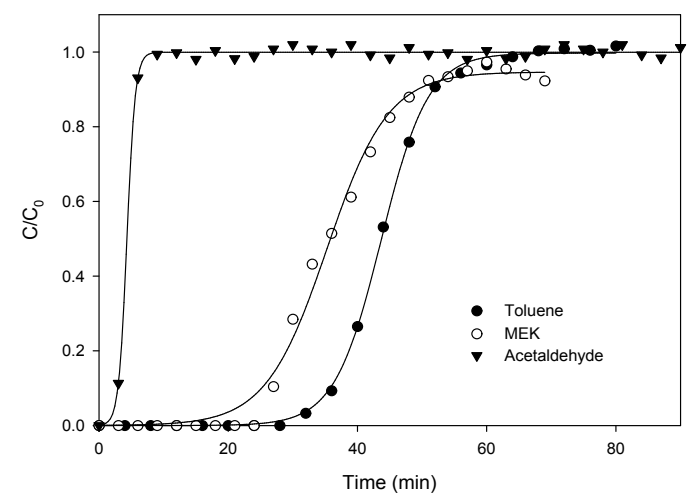

[그림 4] $\mathrm{ACF}_{\mathrm{C} 1}$ 의 $\mathrm{VOC}$ 종류별 흡착 특성

[표 3] $\mathrm{ACF}_{\mathrm{C} 1}$ 의 $\mathrm{VOC}$ 종류별 흡착량

\begin{tabular}{|c|c|c|c|}
\hline & Toluene & MEK & Acetaldehyde \\
\hline $\begin{array}{c}\text { 흡착량 } \\
(\mathrm{g} / \mathrm{g} \text { of } \mathrm{ACF})\end{array}$ & 0.307 & 0.208 & 0.004 \\
\hline
\end{tabular}

\section{2 온도에 따른 흡착 특성}

본 실험에서는 흡착층 조업온도에 따른 흡착량의 변화 를 조사하기 위해 $\mathrm{ACF}_{\mathrm{Cl}}$ 흡착제를 이용하여 흡착층의 온 도를 각각 $25^{\circ} \mathrm{C}, 35^{\circ} \mathrm{C}, 45^{\circ} \mathrm{C}$ 로 변화시키면서 톨루엔과 $\mathrm{MEK}$ 에 대한 흡착특성을 그림 5에 나타내었다.

그림 5 에서 흡착층의 온도가 증가함에 따라 파과시간 이 톨루엔과 MEK 모두 빨라짐을 알 수 있다. 이는 흡착 층의 온도 증가에 따른 흡착물의 확산계수가 증가하여 흡착제의 기공 내부에서의 확산이 용이해지면서 $\mathrm{MTZ}$ 의 길이가 짧아졌기 때문이다. 그리고 그림 5의 파과곡선으 로부터 구할 수 있는 흡착량을 비교해보면 온도증가에 따라 톨루엔의 경우 약 $16 \%, \mathrm{MEK}$ 의 경우 약 $9 \%$ 정도 감소함을 알 수 있으며, 김한수 등도 온도에 따른 흡착량 비교에서 유사한 결과가 일어남을 보고하고 있다[10].

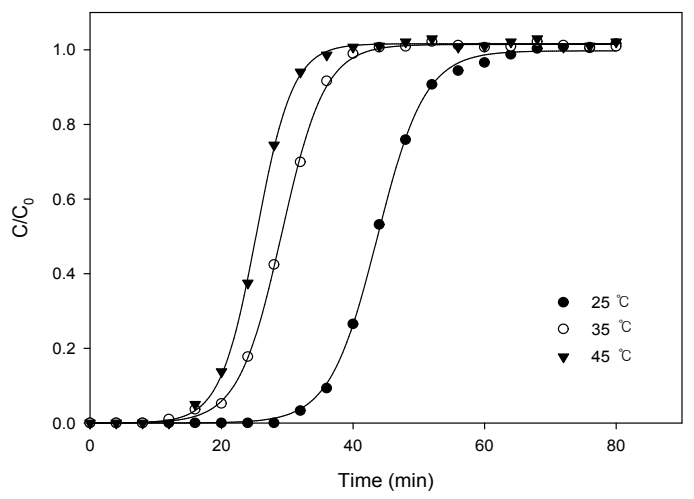

(a) Toluene

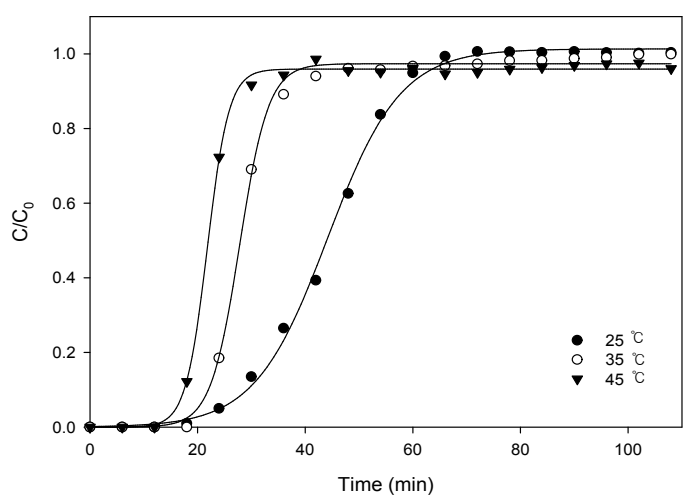

(b) MEK

[그림 5] 톨루엔과 $\mathrm{MEK}$ 의 온도변화에 따른 흡착특성

\section{3 활성탄소섬유의 탈착특성}

흡착제를 선정함에 있어 탈착특성 또한 중요한 요소 
중의 하나이다. 탈착 여하에 따라 흡착제의 수명은 물론 재생되어지는 휘발성 유기화합물의 양과 질 등의 상업적 부분에 영향을 줄 수 있기 때문이다. 특히 활성탄소섬유 의 경우 활성탄보다 빠른 흡착 kinetics를 가지면서 더 좋 은 효율의 흡착특성을 나타내며, 활성탄에 비하여 불순물 의 양이 적기 때문에 탈착시 회수용제의 품질이 매우 우 수한 것으로 알려져 있다.

따라서 본 연구에서는 탈착층의 온도를 1 분 이내에 $200^{\circ} \mathrm{C}$ 까지 급격하게 상승시킨 후 2 시간 동안 유지시키면 서 탈착 과정에서 발생하는 흡착물의 탈착특성을 그림 6 에 나타내었다. 그림에서 활성탄소섬유의 경우 약 5 분 전·후로 약 $99 \%$ 이상이 탈착되었으나, 활성탄의 경우 20 분경부터 $99 \%$ 가 탈착됨을 알 수 있다. 이는 활성탄의 경 우 비교적 큰 기공을 가지므로 기공 깊숙하게 흡착되어 진 흡착물이 세공 밖으로 빠져나오는 경로가 길기 때문 이다[9].

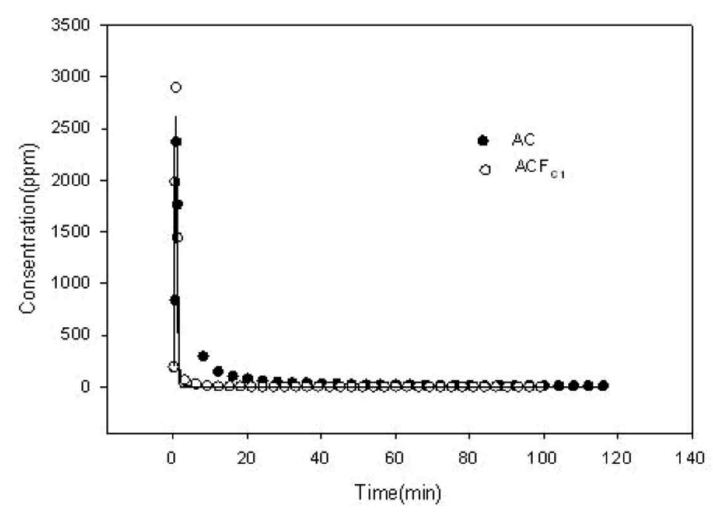

[그림 6] 활성탄소섬유와 활성탄의 흡착특성

\section{4. 결론}

기존에 주로 사용되었던 활성탄을 대신할 수 있는 활 성탄소섬유를 이용하여 대표적 휘발성유기화합물질인 톨 루엔과 MEK의 흡 - 탈착 특성을 연구하였다.

그 결과 활성탄소섬유의 경우 표면적이 높을수록 파과 시간이 증가하였으며, $\mathrm{ACF}_{\mathrm{J}}$ 의 경우 활성탄에 비하여 약 1.15 배 높은 흡착량을 보였다. $\mathrm{VOC}$ 종류별 흡착특성의 경우에는 흡착물질의 분자량이 높을수록 파과시간이 증 가하여 보다 높은 흡착량을 나타내었다. 또한 흡착층의 온도가 증가함에 따라 파과시간 및 흡착량은 감소하였다. 그리고 활성탄과 활성탄소섬유의 탈착성능은 약 $99 \%$ 탈 착되기까지 활성탄은 20 분 활성탄소섬유는 5 분으로 활성 탄소섬유가 약 4 배 빠르게 탈착됨을 알 수 있었다.

\section{참고문헌}

[1] Jong-Bo Kim, Jong-Chan Kim, Seung-Seok Choi, Heung-Bin Im, "A study on the VOCs Contamination of Ambient Air in Kyonggi-do Area", Korean J. Sanitation, 17, 2, pp. 63-70, 2002.

[2] 변용수, 정석우, 유상오, 유문하, 전동환, “ $\mathrm{ACF}$ 와 활 성탄을 이용한 톨루엔과 IPA의 흡/탈착 성능특성”, Applied Chemistry, 13, 1, pp. 65-68, 2009.

[3] 손미숙, 김상도, 우광재, 박희재, 서만철, 이시훈, 유 승곤, "탄소흡착제에 의한 삼성분계 휘발성 유기화합 물의 흡착특성”, Korean Chem. Eng. Res., 44, 6, pp. 669-675, 2006.

[4] Dong-Cheul Moon, Kwang-Ho Lee, Chang-Soo Kim, Do-Hyung Kim, Mi-Ran Kim, Chae-Ho Shin, Il-Young Park, Seoung-Youl Nam, Chang-Gi Lee, "Micropore Analysis and Adsorption Characteristics of Activated Carbon Fibers", ANALYTICAL SCIENCE and TECHNOLOGY, 13, 10, pp. 89-95, 2000.

[5] 이승재, 문승현, “세탁소 배출 휘발성 유기화합물의 흡착 제거 기술”, 대한환경공학회지, 제 31 권, 11 호, pp. 1025-1032, 2009.

[6] L. I. Jing, L. I. Zhong, L. I. U. Bing, XIA. Qibin, XI. Hongxia, "Effect of relative humidity on adsorption of formaldehyde on modifid activated carbon", Chin. J. Chem. Eng, 16, 6, pp. 871-875, 2008.

[7] L. Luo, D. Ramirez, M. J. Rood, G. Grevillot, K. J. Hay, D. L. Thurston, "Adsorption and electrothermal desorption of organic vapor using activated carbon adsorbents with novel morphologies", Carbon, 44, pp. 2715-2733, 2006.

[8] Zheng-Hong Huang, Feiyu Kang, Kai-Ming Liang, Jiming Hao, "Breakthrough of methylethylketone and benzene vapors in activated carbon fiber beds", Journal of Hazardous Materials, 3978, pp. 1-9, 2003.

[9] 원정일, 김기환, 신창섭, “열탈착법 적용을 위한 $\mathrm{AC}$ 및 $\mathrm{ACF}$ 의 공기중 유기용제 흡.탈착특성”, 한국안전학 회, 11, 4, pp. 377-383, 2000.

[10] Han-Soo Kim, Yeong-Seong Park, “Adsorption Characteristics of Volatile Organic Compounds -BTX on Activated Carbon Fiber", J. KOSAE, 15, 6, pp. 805-812, 1999. 
백 근 호(Geun-Ho Baek)

[준회원]

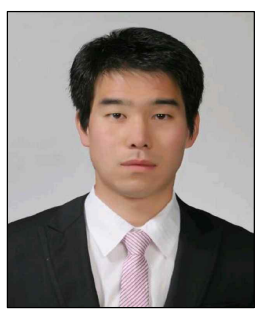

- 2009년 2월 : 군산대학교 환경 공학과(공학사)

- 2011년 2월 : 군산대학교 토목 환경공학부(공학석사)

<관심분야>

이산화탄소 포집기술, $\mathrm{VOCs}$ 흡착

김 정 수(Jung-Su Kim)

[정회원]

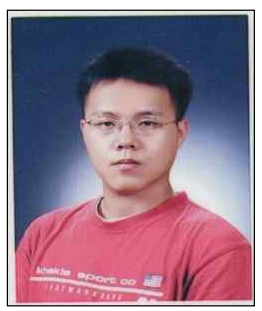

- 2002년 2월 : 군산대학교 토목환 경공학부 환경공학과(공학사)

- 2004년 2월 : 군산대학교 토목환 경공학부(공학석사)

- 2004년 3월 2011년 2월 : (주)유성환경

<관심분야>

$\mathrm{VOC}$ 흡착, 폐기물 가스화 및 열분해

장 현 태(Hyun-Tae Jang)

[정회원]

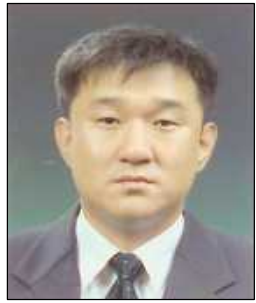

1986년 2월 : 고려대학교 화학공 학과(공학사)

- 1991년 8월 : 고려대학교 화학공 학과(공학석사)

- 1996년 2월 : 고려대학교 화학공 학과(공학박사)

- 1994년 3월 현재 : 한서대학 교 화학공학과 교수

<관심분야>

흡착, 유동층반응
김 형 완(Hyeong-Wan Kim)

[정회원]

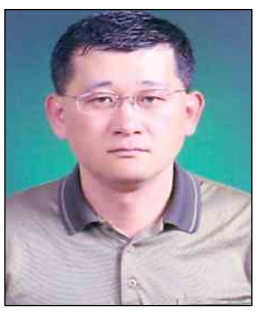

- 2001년 2월 : 군산호원대학교 토 목공학과(공학사)

- 2009년 2월 : 군산대학교 토목공 학과(공학석사)

- 2011년 2월 : 군산대학교 토목공 학과 수료 (공학박사)

<관심분야>

지반공학, 흡착

김 형 주(Hyeong-Joo Kim)

[정회원]

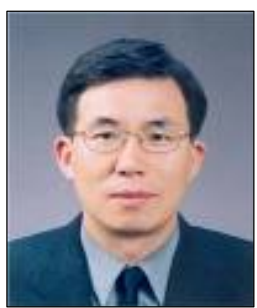

- 1983년 2월 : 고려대학교 토목공 학과(공학사)

- 1985년 2월 : 고려대학교 토목공 학과(공학석사)

- 1990년10월 : 일본히로시마대학 공학연구과(공학박사)

- 1992년 9월 현재 : 군산대학교 토목공학과 교수

<관심분야>

지반공학, 흡착

[정회원]

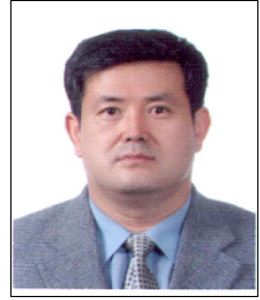

1981년 8월 : 고려대학교 화학공 학과(공학사)

- 1985년 2월 : 고려대학교 화학공 학과(공학석사)

- 1993년 8월 : 고려대학교 화학공 학과(공학박사)

- 1994년 3월 현재 : 군산대학 교 토목환경공학부 교수

<관심분야>

폐기물 가스화 및 열분해 